\title{
A structural model of well-being, spontaneity and self- efficacy: Italian validation between adolescents and young adults
}

\author{
Um modelo estrutural entre bem-estar, espontaneidade e autoeficácia: \\ validação italiana entre adolescentes e adultos jovens
}

Lucia Ronconi, ${ }^{1}$ Noemi Giannerini, ${ }^{1}$ Ines Testoni, ${ }^{1}$ Maria Zulian, ${ }^{1}$ Maria Silvia Guglielmin ${ }^{2}$

\begin{abstract}
Introduction: The passage from adolescence to young adulthood introduces many challenges and chances aimed at promoting independence, financial self-sufficiency, assumption of responsibilities and separation from parents. Literature shows that in the continuum between these two phases of life, many factors intervene, producing significant differentiations.

Methods: This study considered three dimensions - well-being, measured through the Clinical Outcomes in Routine EvaluationOutcome Measure (CORE-OM); spontaneity, measured through the Spontaneity Assessment Inventory-Revised (SAI-R); and self-efficacy, measured through the General Self-Efficacy scale (GSE). The study involved two groups of Italian participants: 495 adolescents, aged between 13 and 19 years, selected at a high school; and 368 young adults, aged between 18 and 30 years, recruited by snowball sampling.

Results: Results of confirmatory factor analysis for each instrument in each group indicate the validity of the three instruments for both age groups. No significant differences were found between adolescents and young adults on total or subtotal scores of the CORE-OM, except for the risk factor. Conversely, the mean scores obtained with SAI-R and GSE were very different between adolescents and young adults.

Conclusions: The results of path analysis show a significant mediation of spontaneity in the link between self-efficacy and all specific psychological distress domains for adolescents. Instead, there is a significant mediation of spontaneity between selfefficacy and all specific psychological distress domains except the risk domain for young adults.

Keywords: Clinical Outcomes in Routine Evaluation-Outcome Measure (CORE-OM), Spontaneity Assessment InventoryRevised (SAI-R), General Self-Efficacy scale (GSE), adolescence, adulthood.
\end{abstract}

Resumo

\begin{abstract}
Introdução: A transição da adolescência para a idade adulta envolve muitos desafios e oportunidades de promover independência, autossuficiência financeira, assunção de responsabilidades e a saída da casa dos pais. A literatura mostra que, na passagem entre essas duas fases do ciclo vital, muitos fatores podem intervir, gerando mudanças significativas.

Métodos: Este estudo considerou três dimensões psíquicas: bemestar, investigado através do Clinical Outcomes in Routine EvaluationOutcome Measure (CORE-OM); espontaneidade, investigada através do Spontaneity Assessment Inventory-Revised (SAI-R); e autoeficácia, investigada por meio da escala General Self-Efficacy (GSE). O estudo envolveu dois grupos de participantes italianos: 495 adolescentes com idade entre 13 e 19 anos, selecionados em uma escola de ensino médio; e 368 jovens adultos com idade entre 18 e 30 anos, recrutados por meio de amostragem em bola de neve.

Resultados: Os resultados da análise fatorial confirmatória para cada instrumento em cada grupo indicaram a validade dos três instrumentos para as duas faixas etárias. Não foram observadas diferenças significativas entre adolescentes e jovens adultos nos resultados total e subtotal do CORE-OM, exceto pelo fator risco. Por outro lado, os resultados médios obtidos nos instrumentos SAI-R e GSE foram muitos diferentes entre adolescentes e jovens adultos.

Conclusões: Os resultados da análise fatorial mostram uma mediação significativa da espontaneidade entre a autoeficácia e todos os domínios das dificuldades psicológicas específicas dos adolescentes. Em contraste, há uma mediação significativa da espontaneidade entre a autoeficácia e todos os domínios específicos das dificuldades psicológicas dos jovens adultos, exceto para o domínio risco.

Descritores: Clinical Outcomes in Routine Evaluation-Outcome Measure (CORE-OM), Spontaneity Assessment Inventory-Revised (SAI-R), General Self-Efficacy scale (GSE), adolescência, vida adulta.
\end{abstract}

\footnotetext{
${ }^{1}$ FISPPA - Dipartimento di Filosofia, Sociologia, Pedagogia e Psicologia Applicata, Università degli Studi di Padova, Padova, Italy. ${ }^{2}$ Scuola di Psicodramma di Treviso, Treviso, Italy.

Submitted Jun 02 2017, accepted for publication Nov 092017.

Suggested citation: Ronconi L, Giannerini N, Testoni I, Zulian M, Guglielmin MS. A structural model of well-being, spontaneity and self-efficacy: Italian validation between adolescents and young adults. Trends Psychiatry Psychother. 2018;40(2):136-143. http://dx.doi.org/10.1590/2237-6089-2017-0072
} 


\section{Introduction}

Generally, in Western countries, the age between adolescence and young adulthood is characterized by many key developmental tasks to face, including consolidating the physical changes taking place after puberty, forming a social identity, obtaining higher education by attending secondary school and the university, leaving the childhood home, entering the workforce, forming intimate and long-term relationships, and starting a family. The passage from adolescence to young adulthood introduces the construction of independence by creating financial self-sufficiency, accepting responsibility, developing personal beliefs separate from their parents, and establishing equal adult relationships with their parents. ${ }^{1}$ All these changes may be particularly stressful, and therefore research has analyzed the importance of well-being in this period of life. Well-being is the state of successful performance throughout the life course, integrating physical, cognitive, emotional and social functions that produce the subjective feelings of contentment, happiness, satisfaction with one's life experiences and role in the world of work, source of achievement, utility, and absence of distress, dissatisfaction, or worry. ${ }^{2}$ Since these two ages are different, because young adults have a sense of direction, in terms of the careers they have chosen, and work towards establishing a firm base for themselves, differently from adolescents, the focus of this study was to gain an understanding of some constructs that can intervene in well-being during such developmental phases, namely, spontaneity and selfefficacy.

The relationship between spontaneity and selfefficacy in adults has already been shown in the area of psychodrama research. ${ }^{3}$ In fact, spontaneity is a psychological construct not easily definable, which assumes an important role in the foundation of psychodrama. ${ }^{4}$ It was elaborated by Jacob Moreno, who defined it as "a response of an individual to a new situation and the new response to an old situation"5(p.50) and tried to operationalize such an idea in some early works. ${ }^{6-9}$ For a long time, only the non-standardized spontaneity test introduced by the author was used, ${ }^{5}$ which consists of observing and evaluating people's performance in different situations. From this initial endeavor, some studies derived, among which Meyer's ${ }^{10}$ and the one by Steitzel \& Hughey. ${ }^{11}$ Finally, Kipper \& Hundal ${ }^{12}$ introduced a new instrument, called Spontaneity Assessment Inventory (SAI), after which some studies were conducted to describe characteristics of spontaneity, e.g., acting from natural free will, lacking premeditation, thinking of the direction and the constraint implied by realistic and efficacious actions. ${ }^{3,12-15}$ Research finally confirmed that spontaneity correlates positively with the tendency to focus on behavior, feelings and thoughts related to the present situations, ${ }^{14}$ and correlates negatively with emotional inhibition. ${ }^{16}$

Perceived self-efficacy refers to the belief in one's own capabilities to produce a given attainment, encouraging perseverance through difficulties. ${ }^{17,18} \mathrm{~A}$ lack of this feeling, which concerns the belief of being able to control challenging situational demands, is associated with stress, depression, anxiety, and hopelessness. ${ }^{18}$ Even though Bandura et al. ${ }^{18}$ consider it as a domainspecific concept, some researchers provided findings that support the existence of a generalized sense of self-efficacy, which is strictly intertwined with selfconfidence. ${ }^{19}$ Perceived self-efficacy influence people's thoughts and behaviors and their emotional reactions to situations; furthermore, it determines how much effort they will expend facing obstacles. ${ }^{20}$ Spontaneity seems to be linked to self-efficacy, since it seems to be thought of as psychological energy that propels the individual to act adequately, without latent inhibitions, guilt, or self-doubts. ${ }^{21}$ Research has shown the relationship between well-being and self-efficacy, 3,15,22 while in turn psychodrama improves the level of wellbeing, spontaneity and self-efficacy in adults. ${ }^{23}$

This study was undertaken to investigate whether spontaneity and self-efficacy have impacts on wellbeing in both adolescence and young adulthood, and whether there are differences between the two age groups or not.

\section{Aims and hypothesis}

Considering that spontaneity is associated with both well-being ${ }^{12,24}$ and self-efficacy, ${ }^{3}$ the purpose of this study was to analyze the psychometric properties of a test battery used to investigate these constructs in a group of adolescents and young adults. The battery consists of three questionnaires: Clinical Outcomes in Routine Evaluation-Outcome Measure (CORE-OM), Spontaneity Assessment Inventory-Revised (SAI-R) and General Self-Efficacy (GSE). This work is divided in three parts: in the first part, we administer the test battery to a group of young adults and another group of adolescents; in the second part, we observe the differences between the two groups; in the third part, we test the mediation role of spontaneity in the relationship between self-efficacy and well-being.

The function of this battery is its usefulness in exante and ex-post interventions of psychodrama for educative programs, in order to observe changes in the participants. 


\section{Methods}

\section{Adolescents}

The participants were 495 adolescents ( 287 female, 203 male) recruited at a high school in Northern Italy, aged between 13 and 19 years (mean \pm standard deviation $=15.43 \pm 1.50)$. With regard to the family situation, the group was characterized as follows: 81 were only child $(16.5 \%), 304$ had one brother or sister $(62 \%)$, and 105 had more than one sibling (21.4\%). Furthermore, 36 participants had separated parents (7.9\%), 31 divorced (6.8\%) and 385 married (84.2\%); 5 did not answer this question. Most of the adolescents were single $(77.4 \%)$, and 111 were involved in a relationship (22.6\%).

After delivering the informed consent form to the participants' parents, the battery was administered during school time. Each participant had a personal computer and the operation lasted 30 minutes.

\section{Young adults}

The research involved 368 participants (194 male, 174 female), aged between 18 and 30 years

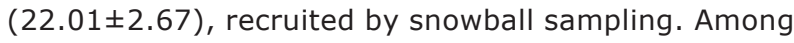
them, 307 participants were students (83\%), 19 were employed $(5.2 \%), 11$ were workmen $(3 \%)$ and 17 were freelance professionals (4.6\%). Seventytwo participants were graduated (20\%) and 276 had a high-school diploma (75\%). Also, 360 participants were unmarried $(97.8 \%)$ and five had children. The informed consent form was delivered along with the self-report questionnaire, and the young adult participants were advised about the study aims and procedures, being assured that participation was voluntary. The confidentiality of their responses was guaranteed. Informed consent was obtained from all participants.

The entire study followed Ethical Principles of Psychologists and Code of Conduct of the American Psychological Association and the principles of the Declaration of Helsinki.

\section{Measures}

Clinical Outcomes in Routine Evaluation-Outcome Measure (CORE-OM)

The CORE-OM was used in order to measure the level of well-being. CORE is a generic self-report measure of psychological distress. It was created as a brief, userfriendly questionnaire to assess and measure outcomes in psychological interventions. The CORE System is comprised of three instruments: CORE Assessment Form, CORE End of Therapy Form and CORE-OM. Only the last one was used in the present study.
The questionnaire consists of 34 items that measure how the participant felt during the last week; each item is evaluated on a 5-point Likert scale, ranging from 0 (not at all) to 4 (most or all of the time). Items can be divided in four domains: subjective well-being (4 items), problems (12 items), functioning (12 items) and risk (to self: 4 items; to others: 2 items). Higher scores on all domains indicate more distress, and the mean score of the item completed represents the total score.

Lyne et al. ${ }^{25}$ stated that the CORE-OM may be best scored as two scales: risk and psychological distress, which include the three remaining scales. Evans et al. ${ }^{26}$ observed good internal and test-retest reliability of the CORE-OM (0.75-0.95) and good convergent validity with seven other instruments. Furthermore, the questionnaire revealed large differences between clinical and non-clinical samples.

The Italian version of the CORE-OM ${ }^{27}$ has also shown good psychometric parameters: internal consistency was alpha $>0.90$ and concurrent validity ranged from 0.79 to 0.87 for all the domains. There were statistically significant differences between clinical and non-clinical datasets on all scores.

\section{Spontaneity Assessment Inventory-Revised (SAI-R)}

This is the revised version of the original SAI, ${ }^{12}$ modified by Kipper \& Shemer, ${ }^{24}$ who eliminated two idiomatic items and reduced the points of the Likert scale. The questionnaire was created to measure the occurrence of spontaneous state in people during day life. The SAI-R, like the original version, poses one initial question: "How strongly do you have these feelings and thoughts during a typical day?" The 18 items that follow represent peculiar feelings and thoughts in a spontaneous state, such as "energized" and "uninhibited," and their occurrence during a typical day is measured on a 5-point Likert scale, ranging from 1 (very weak) to 5 (very strong). The total sum of the ratings of all the items represents a measure of the intensity of spontaneity. The Cronbach's alpha for the SAI-R was 0.79. ${ }^{24}$ Other studies have already used the SAI-R as a measure of spontaneity. ${ }^{12,16}$

The Italian validation of the SAI- ${ }^{24}$ showed good internal consistency (alpha $=0.81$ ), with a mean score of $57.05 \pm 8.09$. Moreover, research has shown a negative correlation between SAI-R and BDI-II ( $r=$ $-0.33) / C O R E-O M(r=-0.47)$, as indicated previously. ${ }^{24}$

\section{General Self-Efficacy scale (GSE)}

The GSE is a unidimensional scale that evaluates the belief in one's own competence to deal with stressful or challenging situations. The original version of the GSE was developed by Schwarzer \& Jerusalem in 1979 and 
comprised 20 items, which were later reduced to 10 . A typical item is "I can always manage to solve difficult problems if I try hard enough." The subjects respond on a 4-point Likert scale ranging from 1 (not at all true) to 4 (exactly true). A higher total score is indicative of higher levels of self-efficacy. The GSE scale was translated into 28 languages. ${ }^{28}$ Scholz et al. ${ }^{29}$ examined the psychometric properties of the instrument in 25 countries, concluding that the construct of perceived self-efficacy is international and that the GSE is an equivalent measure across different cultures. Cronbach's alphas ranged from 0.79 to 0.90 .

The Italian adaptation of the GSE scale was developed by Sibilia et al. ${ }^{30}$ Testoni et al. ${ }^{31}$ obtained a good value for internal consistency of the GSE in the Italian population (alpha $=0.77$ ).

\section{Statistical analysis}

All measures were previously validated for the general population in Italy and showed good reliabilities in our samples (i.e., Cronbach's alphas). Because our samples are characterized by low age, especially the adolescent sample, we decided to test the latent structure before conducting the mediation analyses. Initially, we used confirmatory factor analysis to test the relationship between items and latent variables for SAI-R, CORE-OM and GSE in the adolescent sample using the LISREL 8.80 program. Subsequently, we computed the means of total and subtotal scores, used Pearson's correlations to study associations among the variables in each sample, and used Student's $t$ test to examine differences between adolescents and young adults using the Statistical Package for the Social Sciences (SPSS) version 24. Finally, we used path analysis to test the mediation role of spontaneity in the relationship between self-efficacy and well-being in each sample, using the Sobel test for mediation, also known as the product of coefficients approach, ${ }^{32,33}$ in the LISREL 8.80 program.

To evaluate the goodness of fit of the models for confirmatory factor analyses and path analysis, several indices were taken into consideration. Since the $x^{2}$ statistic is extremely sensitive to sample size, two relative fit indices were considered: the non-normed fit index (NNFI) and the comparative fit index (CFI), as they both perform well with small and large samples. For these indices, values $>0.95$ are associated with an adequate fit. $^{34}$ The root mean square error of approximation (RMSEA) was also used. This is an absolute fit index that assesses the approximation of parameter estimates to true parameters in the population. RMSEA values $<0.08$ can be considered as an adequate fit. $^{34}$

\section{Results}

\section{Confirmatory factor analysis}

For the CORE-OM, we tested a second-order model with four first-order factors - subjective well-being, problems, functioning, risk - and one higher-order factor representing general, not domain specific, psychological distress. All fit index values for this model were adequate (Table 1 ) and confirmed the validity of both the subtotals and the global total for the CORE-OM in the adolescent sample.

For the SAI-R, the initial model, specifying one factor and no error correlations, was not fully adequate in the adolescent sample ( $X^{2}=892.09$; degrees of freedom [df] $=135 ; n=490 ; p<0.001 ;$ RMSEA $=0.110 ;$ CFI $=0.88 ; \mathrm{NNFI}=0.87$ ). Post-hoc modifications of this model allowing error correlations produced a model with an acceptable fit and an interpretable factor structure (Table 1). We added six error correlation parameters, all consistent with the literature ${ }^{3,14}$ : between items "Creative" and "Free to invent"; between items "Things seem to flow" and "Living fully with balance"; between items "Alive" and "Fulfilled"; between items "Successful" and "Powerful"; between items "Uninhibited" and "Pleasure"; between items "Exhilarated" and "Powerful."

For the GSE, the one factor model showed a good fit to the data in the adolescent sample (Table 1 ).

Table 1 - Results of confirmatory factor analyses of the instruments in the adolescent sample

\begin{tabular}{|c|c|c|c|c|c|c|}
\hline stionnaires & Model & Chi-square & df & RMSEA & CFI & NNFI \\
\hline Clinical Outcomes in Routine Evaluation- & 4-factor + 1-factor & 1649.55 & 523 & 0.069 & 0.95 & 0.95 \\
\hline 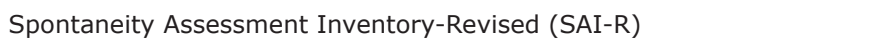 & 1-factor modified* & 01 & 129 & 0.072 & 0.95 & 0.94 \\
\hline General Self-Efficacy scale (GSE) & 1 -factor & 93.87 & 35 & 0.059 & 0.98 & 0.97 \\
\hline
\end{tabular}

CFI = comparative fit index; $d f=$ degrees of freedom; NNFI = non-normed fit index; RMSEA = root mean square error of approximation.

* Six error correlation parameters were added to original model. 


\section{Adolescents and young adults differences}

The mean scores of the CORE-OM were very similar in the adolescent and young adult samples (Table 2): no significant differences were found on total and subtotal scores, except for the risk factor $\left(t_{[860]}=2.22 ; p=\right.$ 0.026). The adolescents showed higher scores on the tendency to risk when compared to the young adults $(0.30 \pm 0.55$ vs. $0.22 \pm 0.49)$.

Conversely, the mean scores of the SAI-R and GSE were very different in adolescents and in young adults: significant differences were found on the SAI-R total score $\left(t_{[860]}=2.88 ; p=0.004\right)$, and also on the GSE total score $\left(t_{[860]}=4.79 ; p=0.001\right)$. Adolescents showed higher scores of spontaneity than young adults

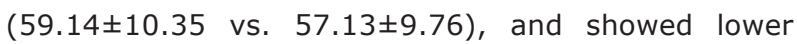
levels of self-efficacy than young adults $(27.74 \pm 4.74$ vs. $29.27 \pm 4.46)$.

All correlations between the study variables were significant at 0.01 level, except two correlations of the CORE-OM risk factor in the young adult sample, with SAI-R and GSE, respectively (Table 3). The CORE-OM showed negative correlations with SAI-R and GSE; in turn, GSE and SAI-R were positively correlated.

\section{Path analysis}

Path analysis was used to evaluate the contributions of perceived self-efficacy and spontaneity to values of psychological distress among adolescents and young adults in each specific domain, at a multivariate level. Gender was inserted in the model as a covariate. In order to get to the most parsimonious model, we preliminarily tested path coefficients of the control variable gender across models. As a result, the paths from gender on spontaneity and from gender on three specific psychological distress domains - problems, functioning, risk - were removed from the model, since they were nonsignificant in both groups. This model was tested separately for the two groups and fit indices were adequate for both adolescents $\left(X^{2}=6.34 ; \mathrm{df}=4\right.$; $\mathrm{n}=490 ; \mathrm{p}=0.175 ; \mathrm{RMSEA}=0.035 ; \mathrm{CFI}=1.00 ; \mathrm{NNFI}$ $=0.99)$ and young adults $\left(X^{2}=17.29 ; 4 ; n=367 ; \mathrm{p}\right.$ $=0.002 ;$ RMSEA $=0.095 ;$ CFI $=0.99 ;$ NNFI $=0.94)$, providing a better fit to the data in the adolescent group.

The whole model accounted for different shares of the variance for each specific psychological distress domain (38\% for subjective well-being; $22 \%$ for problems; $40 \%$

Table 2 - Cronbach's alpha values, means and standard deviations of all study variables according to sample

\begin{tabular}{|c|c|c|c|c|c|c|}
\hline \multirow[b]{2}{*}{ Variable } & \multicolumn{3}{|c|}{ Adolescents } & \multicolumn{3}{|c|}{ Young adults } \\
\hline & Cronbach's a & Mean & SD & Cronbach's a & Mean & SD \\
\hline CORE-OM total & 0.92 & 1.01 & 0.57 & 0.92 & 1.04 & 0.57 \\
\hline CORE-OM subjective well-being & 0.72 & 1.32 & 0.88 & 0.66 & 1.39 & 0.84 \\
\hline CORE-OM problems & 0.86 & 1.01 & 0.72 & 0.88 & 1.20 & 0.78 \\
\hline CORE-OM functioning & 0.79 & 1.22 & 0.59 & 0.74 & 1.18 & 0.55 \\
\hline CORE-OM risk & 0.78 & 0.30 & 0.55 & 0.82 & 0.22 & 0.49 \\
\hline SAI-R total & 0.86 & 59.14 & 10.35 & 0.86 & 57.13 & 9.76 \\
\hline GSE total & 0.84 & 27.74 & 4.74 & 0.85 & 29.27 & 4.46 \\
\hline
\end{tabular}

CORE-OM = Clinical Outcomes in Routine Evaluation-Outcome Measure; GSE = General Self-Efficacy scale; SAI-R = Spontaneity Assessment Inventory-Revised; $\mathrm{SD}=$ standard deviation.

Table 3 - Correlation matrix for all study variables according to sample

(adolescents in lower triangle and young adult in upper triangle)*

\begin{tabular}{|c|c|c|c|c|c|c|c|}
\hline Variable & 1 & 2 & 3 & 4 & 5 & 6 & 7 \\
\hline 1. CORE-OM total & - & 0.84 & 0.94 & .088 & 0.63 & -0.35 & -0.29 \\
\hline 2. CORE-OM subjective well-being & 0.85 & - & 0.76 & .071 & 0.36 & -0.42 & -0.35 \\
\hline 3. CORE-OM problems & 0.93 & 0.76 & - & .071 & 0.52 & -0.29 & -0.22 \\
\hline 4. CORE-OM functioning & 0.87 & 0.69 & 0.67 & - & 0.48 & -0.37 & -0.54 \\
\hline 5. CORE-OM risk & 0.68 & 0.46 & 0.56 & .048 & - & $-0.05 \sim$ & $-0.06 \sim$ \\
\hline 6. SAI-R total & -0.57 & -0.59 & -0.47 & -0.61 & -0.21 & - & 0.49 \\
\hline 7. GSE total & -0.43 & -0.47 & -0.33 & -0.51 & -0.10 & 0.61 & - \\
\hline
\end{tabular}

* All correlations are significant at level 0.01 , except for correlations indicated with $\sim$. 
for functioning; $5 \%$ for risk) and for $37 \%$ of the variance for spontaneity in adolescents, while in young adults the model explained respectively $21 \%$ for subjective wellbeing, $9 \%$ for problems, $17 \%$ for functioning and $0 \%$ for risk for each specific psychological distress domain and $24 \%$ for spontaneity.

Standardized path coefficients calculated separately for the two groups are reported in Figure 1 . The direct and negative links between self-efficacy and the specific psychological distress domains were significant only for subjective well-being and functioning in both groups. The direct and negative link between spontaneity and the specific psychological distress domain of risk was significant only in the adolescent group; for all other domains there was a significant negative direct link with spontaneity in both groups. The effects of gender on subjective well-being and on self-efficacy were significant in both groups, indicating that females had more psychological distress and that they had less selfefficacy than males. Results of the Sobel test supported a mediating role of spontaneity in links between selfefficacy and all specific psychological distress domains for adolescents $(\beta=-0.29, z=-7.78, p<0.001$ for subjective well-being; $\beta=-0.26, z=-6.71, p<0.001$ for problems; $\beta=-0.29, z=-7.61, p<0.001$ for functioning; $\beta=-0.14, z=-2.92, p<0.01$ for risk). Instead, in the young adult group, the Sobel test results supported the mediation of spontaneity for all domains except for the risk domain $(\beta=-0.16, z=-4.96, p<$ 0.001 for subjective well-being; $\beta=-0.12, z=-3.48, p$ $<0.001$ for problems; $\beta=-0.13, z=-3.70, p<0.001$ for functioning; $\beta=-0.01, z=-0.27, p=0.978$ for risk).

a

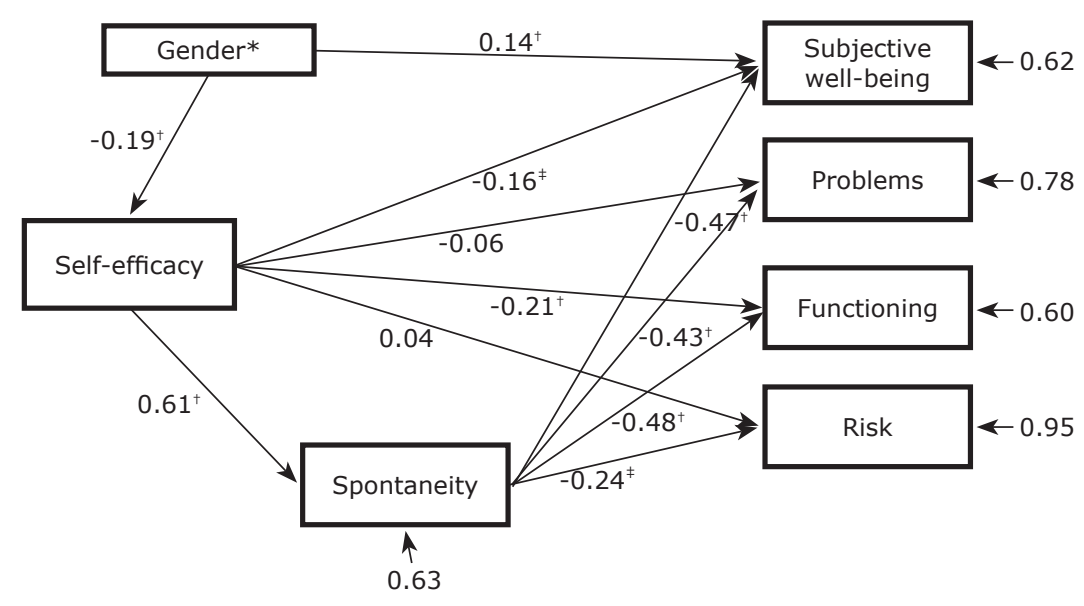

b

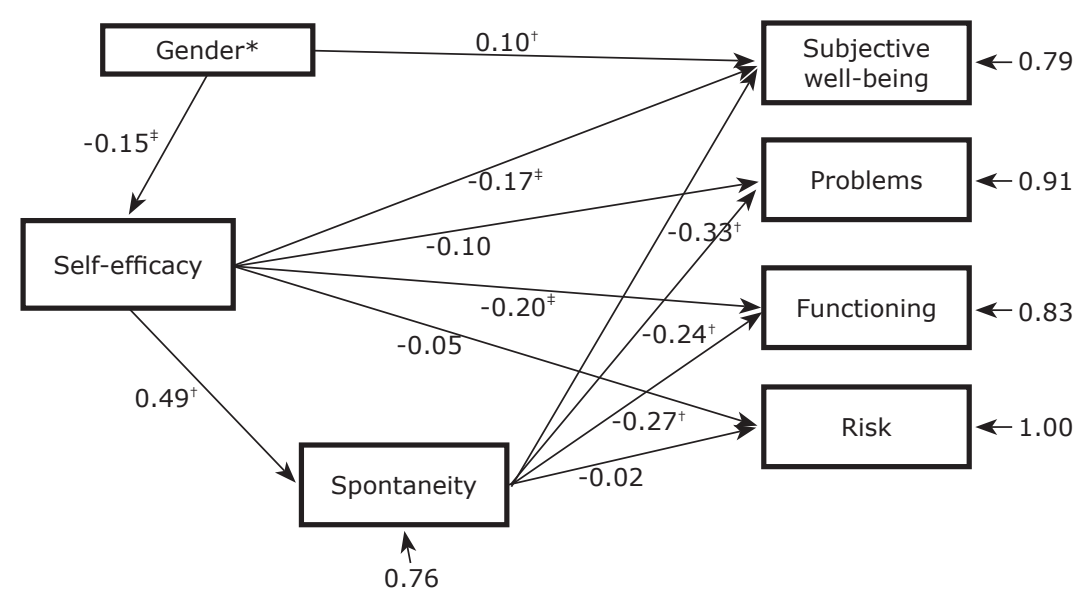

Figure 1 - Path analysis models of the effects of self-efficacy and spontaneity on psychological distress in adolescents (a) $(n=490)$ and in young adults $(b)(n=1295)$. Coefficients are standardized structural coefficients. ${ }^{*}$ Coded $0=$ male and $1=$ female. ${ }^{+} p<0.01$; ${ }^{\ddagger} \mathrm{p}<0.001$. 


\section{Discussion}

Although all measures herein considered, focusing on well-being (measured through the detection of psychological distress), spontaneity and self-efficacy, have been previously validated for the general population in Italy, the present study confirms their validity also for adolescents and young adults.

The present study adds to the researchers' understanding of the differences between adolescents and young adults with regard to spontaneity, selfefficacy and psychological distress.

Adolescents have significantly higher spontaneity scores than young adults. According to Moreno, these results indicate no limitations or restrictions in childhood; only as people grow do they start to limit themselves and to experience anxiety and fear. ${ }^{5,6}$

Self-efficacy is significantly higher in young adults than in adolescents, demonstrating that a person acquires greater knowledge and security of their abilities as they grow. Adolescence is a period of time that requires physical, cognitive and educational changes. Adolescents must make important decisions that require a great sense of responsibility, and the development of a good perception of self-efficacy is crucial to the positive overcoming of this phase. ${ }^{35}$

No significant differences between the well-being of adolescents and young adults have been observed in our study, confirming that adolescents successfully overtake development tasks, which are a source of well-being and self-esteem. ${ }^{36}$ Only in the risk domain, adolescents showed higher scores than young adults, as already stated by other studies. ${ }^{37,38}$ Also, $19 \%$ of adolescents have been shown to perform gestures of self-harm, and 3\% commit serious suicide attempts. ${ }^{39}$

The present study also adds to researchers' understanding of the relationships among spontaneity, self-efficacy and psychological distress in adolescents and young adults.

Self-efficacy and spontaneity are positively correlated, according to Davelaar et al., ${ }^{3}$ who identified how being confident of their abilities led people to behave more spontaneously. The authors ${ }^{3}$ argued that spontaneity is an internal motivational push that is not left to influence external factors but is channeled into appropriate behaviors through the intellectual abilities of the person and taking into consideration their past experiences.

Psychological distress and self-efficacy were negatively correlated, confirming the link between wellness and self-efficacy reported in other studies. ${ }^{40,41}$ Even psychological stress and spontaneity were negatively correlated, confirming the results of Kipper
\& Shemer. ${ }^{24}$ A very low negative correlation was observed for the risk domain with both self-efficacy and spontaneity, significant only in adolescents.

A final purpose of this study was to test a theoretical model linking spontaneity and self-efficacy to psychological distress while controlling for gender effect in adolescents and young adults. It was based on the confirmation that spontaneity and self-efficacy are negatively related to psychological distress; meanwhile, self-efficacy and spontaneity were positively related. This property of the model is in agreement with the literature and confirms that it could be considered as a psychological "trait aspect" instead of a "state aspect," characterizing a wide part of the cycle of life, adolescence included. It would be important to investigate whether this could be extended to childhood. However, the mediating role of spontaneity in the links between self-efficacy and psychological distress showed the presence of a particular difference, which intervenes in the passage from adolescence to young adulthood. Indeed, individuals who are more confident in their abilities are more likely to experience an elevated spontaneous state during day life, which, in turn, is related to lower psychological distress levels, in all dimensions for adolescents and in all domains except risk for young adults. This result suggests that the management of risk undergoes a transformation in this phase of life, and further research could be developed in order to investigate how the loss/improvement of spontaneity in adulthood is related to the awareness of risk. In particular, in adolescents, spontaneity can be attributed to having low self-control and consequently more risk-taking behavior. As shown by Steinberg, ${ }^{42}$ reward-seeking and impulsivity develop along different timetables, and the difference in their timetables helps account for heightened risk-taking during adolescence, while vulnerability to risk-taking in middle adolescence may be due to the combination of relatively higher inclinations to seek rewards and still maturing capacities for self-control. This kind of analysis results useful in the area of psychotherapy, especially with adolescents and young adults who adopt risk behaviors. Indeed, from our study, it emerges that particular attention should be paid to the influence of low or high self-confidence and risk behaviors and how they are related to lack of spontaneity, because of the unconscious assumption of maladaptive or stereotypical roles.

So, the battery validated in the present investigation could be useful in future longitudinal studies designed to investigate the effectiveness of psychodrama interventions in educative settings with adolescents and young adults, and it could also be used to study the relationship between spontaneity and risk in adulthood, 
administering further specific instruments. Moreover, each specific instrument can be used autonomously with adolescents and young adults. According to the literature, ${ }^{40}$ the further development of research with this population could improve the analysis of relationships and differences among creativity, spontaneity and attachment styles with regard to well-being, reasons for living ${ }^{41}$ and spontaneity in adolescence and young adulthood.

A final note inherent to the use of CORE-OM: the authors did not specifically validate the subscales. However, our validation operation showed that its use in the Italian language is possible and also useful.

\section{References}

1. Arnett J]. Conceptions of the transition to adulthood: perspectives from adolescence through midlife. J Adult Dev. 2001;8:133-43.

2. Verma A, Mahajan A, Verma SK. A correlational study of two wellbeing scales. J Pers Clin Studies. 1989;5:93-5.

3. Davelaar MA, Araujo MA, Kipper, DA. The Revised Spontaneity Assessment Inventory (SAI-R): Relationship to goal orientation, motivation, perceived self-efficacy, and self-esteem. Arts Psychother. 2008;35:117-28.

4. Kipper DA, Ritchie TD. The effectiveness of psychodramatic techniques: A meta-analysis. Group Dyn. 2003;7:13-25.

5. Moreno JL. Psychodrama, Vol. 1. Beacon: Beacon House; 1946.

6. Moreno JL. The philosophy of the moment and the spontaneity theater. Sociometry. 1941;4:205-26.

7. Moreno JL. Spontaneity test and spontaneity training. Beacon: Beacon House; 1944.

8. Moreno JL. Who shall survive? Foundation of sociometry, group psychotherapy and sociodrama. Beacon: Beacon House; 1953.

9. Moreno JL, Moreno Z, Moreno J. The discovery of the spontaneous man. Sociometry. 1995;18:155-82.

10. Meyer A. Spontaneity. Sociometry. 1941;4:150-7.

11. Steitzel LD, Hughey AR. Empowerment through spontaneity: A taste of psychodrama. San Jose (CA): Associates for Community Interaction Press; 1994.

12. Kipper D, Hundal J. The Spontaneity Assessment Inventory: the relationship between spontaneity and nonspontaneity. J Group Psychother Psychodrama Sociometry. 2005;58:119-29.

13. Kipper DA, Green DJ, Prora, A. The relationship among spontaneity, impulsivity, and creativity. J Creativity Ment Health. 2010;5:39-53.

14. Christoforou A, Kipper DA. The Spontaneity Assessment Inventory (SAI), anxiety, obsessive compulsive tendencies and temporal orientation. J Group Psychother Psychodrama Sociometry. 2006;58:119-29.

15. Kipper DA. Spontaneity: does the experience match the theory? J Group Psychother Psychodrama Sociometry. 2000;53:33-47.

16. Kipper DA, Davelaar PS, Herst S. The relationship between spontaneity and inhibition. Arts Psychother. 2009;36:329-34.

17. Bandura A. Self-efficacy: The exercise of control. New York: Freeman; 1997.

18. Bandura A, Pastorelli C, Barbaranelli C, Caprara GV. Selfefficacy pathways to childhood depression. J Pers Soc Psychol. 1999; 76:258-69.

19. Judge TA, Erez A, Bono JE, Thoresen, CJ. Are measures of selfesteem, neuroticism, locus of control, and generalized selfefficacy indicators of a common core construct? J Pers Soc Psychol. 2002;83:693-710.

20. Bandura A. Self-efficacy mechanism in human agency. Am Psychologist. 1982;37:122-47.
21. Collins LA, Kumar VK, Treadwell TW, Leach E. The Personal Attitude Scale: A scale to measure spontaneity. J Group Psychother Psychodrama Sociometry. 1997;49:147-56.

22. Catz SL, Felton CG. Psychological distress among minority and low-income women living with HIV. Behav Med. 2002;28:53-60.

23. Testoni I, Guglielmin MS, Pogliani I, Tempra L. Psychodrama and playback theatre for developing self-efficacy: supporting potential development. In: Testoni I, Guglielmin MS, Sageder T, de Leonardis $\mathrm{P}$, editors. Psychodrama, playback theatre \& lifelong learning in action research. Milano: AIPSIM; 2012. p. 23-31.

24. Kipper DA, Shemer H. The Spontaneity Assessment InventoryRevised (SAI-R): Spontaneity, well-being and stress. J Group Psychother Psychodrama Sociometry. 2006;59:127-36.

25. Lyne KJ, Barrett P, Evans C, Barkham M. Dimensions of variation on the CORE-OM. Br J Clin Psychol. 2006;45:185-203.

26. Evans C, Connell J, Barkham M, Margison F, McGrath G, MellorClark J, et al. Towards a standardised brief outcome measure: psychometric properties and utility of the CORE-OM. $\mathrm{Br}$ ] Psychiatry. 2002;180: 51-60.

27. Palmieri G, Evans C, Hansen V, Brancaleoni G, Ferrari S, Porcelli $P$, et al. Validation of the Italian version of the Clinical Outcomes in Routine Evaluation Outcome Measure (CORE-OM). Clin Psychol Psychother. 2009;16:444-9.

28. Schwarzer R, Jerusalem M. Generalized Self-Efficacy scale. In: Weinman J, Wright S, Johnston M. Measures in health psychology: A user's portfolio. Causal and control beliefs. Windsor (UK): NFERNELSON; 1995. p. 35-37.

29. Scholz U, Gutiérrez-Doña B, Sud S, Schwarzer R. Is general selfefficacy a universal construct? Psychometric findings from 25 countries. Eur J Psychol Assess. 2002;18:242-251.

30. Sibilia L, Schwarzer R, Jerusalem M. Italian adaptation of the General Self-Efficacy Scale: Self-Efficacy Generalizzata. 1995 [cited 2003 May 6]. http://userpage.fu-berlin.de/ health/italian. htm

31. Testoni I, Wieser M, Armenti A, Ronconi L, Guglielmin MS, Cottone $P$, et al. Spontaneity as predictive factor for well-being. Instruments for psychodrama: the validation of Spontaneity Assessment Inventory-Revised (SAI-R) and its relationship with psychological suffering and depression in Italy and Austria. In: Stadler C, Wieser M, Kirk K, editors. Psychodrama. Empirical research and science 2. Wiesbaden: Springer; 2016. p. 11-23.

32. Baron RM, Kenny DA. Moderator $\square$ mediator variables distinction in social psychological research: conceptual, strategic, and statistical considerations. J Pers Soc Psychol. 1986;51:1173-82.

33. Hayes AF. Beyond Baron and Kenny: Statistical mediation analysis in the new millennium. Commun Monogr. 2009;76:408-20.

34. Schermelleh-Engel $\mathrm{K}$, Moosbrugger $\mathrm{H}$, Müller $\mathrm{H}$. Evaluating the fit of Structural Equation Models: Tests of significance and descriptive goodness-of-fit measures. Methods Psychol Res Online. 2003;8:23-74.

35. Pajares F, Urdan T, editors. Self-efficacy and adolescence. Greenwich (CT): Information Age; 2015.

36. Codato M, Shaver PR, Testoni I, Ronconi L. Civic and moral disengagement, weak personal beliefs and unhappiness: $A$ survey study of the "famiglia lunga" phenomenon in Italy. TPM Test Psychom Methodol Appl Psychol. 2011;18:87-97.

37. Casey BJ. (2015). Beyond simple models of self-control to circuit-based accounts of adolescent behavior. Annu Rev Psychol. 2015;66:295-319.

38. Steinberg L. Adolescence. New York: McGraw-Hill; 2008.

39. Spirito A, Esposito-Smythers C. Attempted and completed suicide in adolescence. Annu Rev Clin Psychol. 2006;2:237-66.

40. Leganger A, Kraft P, Røysamb E. Perceived self-efficacy in health behavior research: Conceptualisation, measurement and correlates. Psychol Health. 2000;15:51-69.

41. Ronconi L, Testoni I, Zamperini A. Validation of the Italian version of the reasons for living inventory. TPM Test Psychom Methodol Appl Psychol. 2009;16:151-9.

42. Steinberg LD. A dual systems model of adolescent risk-taking. Dev Psychobiol. 2010;52:2

\section{Correspondence:}

Ines Testoni

E-mail: ines.testoni@unipd.it 